\title{
Pre-Service Teachers' Computer Self-Efficacy and the Use of Computers
}

\author{
Admire Chibisa and Mswazi Gladson Tshabalala \\ Department of Mathematics, Science and Technology Education, \\ Faculty of Education, University of Zululand, South Africa \\ https:// orcid.org/0000-0003-3615-4645 \\ https://orcid.org/0000-0002-4060-9529 \\ Mncedisi Christian Maphalala* \\ School of Professional Studies in Education Studies, \\ North-West University, South Africa \\ https://orcid.org/0000-0002-1078-1985
}

\begin{abstract}
The purpose of this study was to examine the effects of preservice teachers' computer self-efficacy on their use of computers. The research used a quantitative design whose data were collected by using a structured five-point Likert scale questionnaire with responses ranging from 1 (strongly agree) to 5 (strongly disagree). Simple random sampling was used to select a representative sample of 400 participants from a population of 4000 pre-service teachers, of which 332 of them were successfully returned, yielding a response rate of $83 \%$. The study employed the Technology-Acceptance Model with eight constructs, namely; demographic influence (DI), social influence (SI), basic computer skills (CS), access to computers (AC), perceived ease of use (PEOU), perceived usefulness (PU), computer self-efficacy (CSE), and actual computer use (AU). Factor analysis was used to analyse the data generated from the survey, with the help of PLS-SEM, using the SmartPLS software version 3.0. The findings of the study indicated that each of the identified factors in the model had a significant effect on CSE. In essence, the identified explanatory variables explained $73.7 \%$ of the variance in CSsE. The four independent variables explained $45.4 \%$ of the variance in PU of computers and $66.5 \%$ of the variance in PEOU of computer use. The CSE model also explained $60.6 \%$ of the variance in computer use. In order to develop a strong CSE for pre-service teachers, it is recommended that higher education institutions ensure that all students have access to the necessary computers, proper connectivity, and skilled technicians.
\end{abstract}

Keywords: pre-service teachers; computer self-efficacy; basic computer skills; access to computers

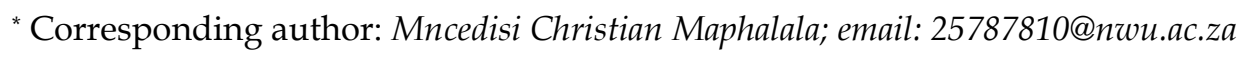




\section{Background to the Study}

Developments in Information and Communication Technologies (ICTs) affect socio-economic issues, such as medicine, banking, agriculture, transportation, engineering, as well as higher education. This has forced many Higher Education Institutions (HEIs) to incorporate technology, such as e-learning into the teaching and learning processes, in orderto enhance learning efficiency and to help gain a competitive edge (Saleh, 2008). The e-Learning activities started in 1955 as Computer-Assisted Instruction (CAI) (Aparicio et al., 2016).

The interactions in e-learning settings comprise human-human, called computermediated communication, and the human-computer interaction (Reichert \& Hartmann, 2004). E-learning was underutilised in the past, especially in developing countries. However, the current crisis of the COVID-19 pandemic has forced the entire world to rely on it for education(Zalat, Hamed and Bolbol: 2021).

According to Suresh et al. (2018), e-learning facilitates the distribution of content at the same time, to a large number of users; e-learning platforms offer many advantages to learners, such as control over the content, control over the time spent in the learning; and consequently the process can be adapted, according to the learner's needs and the objectives of learning. The e-learning also prepares students to meet the demands of their eventual workplace through synchronous and asynchronous learning environments, resources, and services (DuFrene et al., 2011; Sumak et al., 2011).

Some of these e-learning resources and services include the uploading of Content, Lessons, Student Administration, Assignments, Forums, Wikis, Student Assessment, and Feedback (Costa et al., 2012; Šumak et al., 2011). However, despite the proliferation of e-learning resources and services in HEIs, students vary in their confidence levels concerning the usage of technology (DuFrene et al., 2011). Furthermore, the confidence levels of using computers are affected by the individual's computer self-efficacy (Kent \& Giles, 2017) to use the technology.

Computer self-efficacy is an individual's belief about his/her ability to complete a particular task when using a computer (Compeau \& Higgins, 1995). CSE depends on technological and human factors (Hauser et al., 2012; Hueros et al., 2010). Therefore, this research was interested in understanding the factors affecting an individual's computer self-efficacy (CSE) to use computers. CSE is a key factor in the adoption of ICTs; there is no wonder why it has been researched extensively (Balogun \& Olanrewaju, 2016; Clayton et al., 2017; Hauser et al., 2012; Sarfo et al., 2017).

Unfortunately, very little could be found on the relationship of pre-service teachers' CSE and their use of computers. Therefore, this study aims to examine the effects of pre-service teachers' computer self-efficacy on their use of computers.

The study further sought to answer the following research questions:

RQ1: What are the determinants of pre-service teachers' computer self-efficacy? 
RQ2: What is the effect of pre-service teachers' computer self-efficacy on their computer use?

RQ3: Is there a relationship between pre-service teachers' demographics and their use of computers?

\section{The Theoretical Framework}

This study used the Technology-Acceptance Model (TAM); because it is an appropriate theoretical tool to determine the actual computer use, given the external variables affecting pre-service teachers at the research site. TAM has predicted the acceptability of an information system by an individual (Davis, 1993). The theory states that the acceptability and use of an information system is informed by two distinct factors. These two factors are: the perceived ease-of-use (PEOU) and the perceived usefulness (PU) of the technology.

PEOU is the degree to which an individual believes that the use of a system would be easy. PU is the degree to which an individual believes that the use of a system would improve his performance. PEOU and PU (Figure 1) can influence an individual's attitude towards using technology in their individual capacities. However, PEOU and PU are also interrelated and the PEOU of information technology can directly affect the PU of the same information system. External factors also influence the PEOU and the PU of an information system. The external factors in turn, influence the attitude towards using an information system, thereby leading to the actual use of the information system, or a decision not to use it.

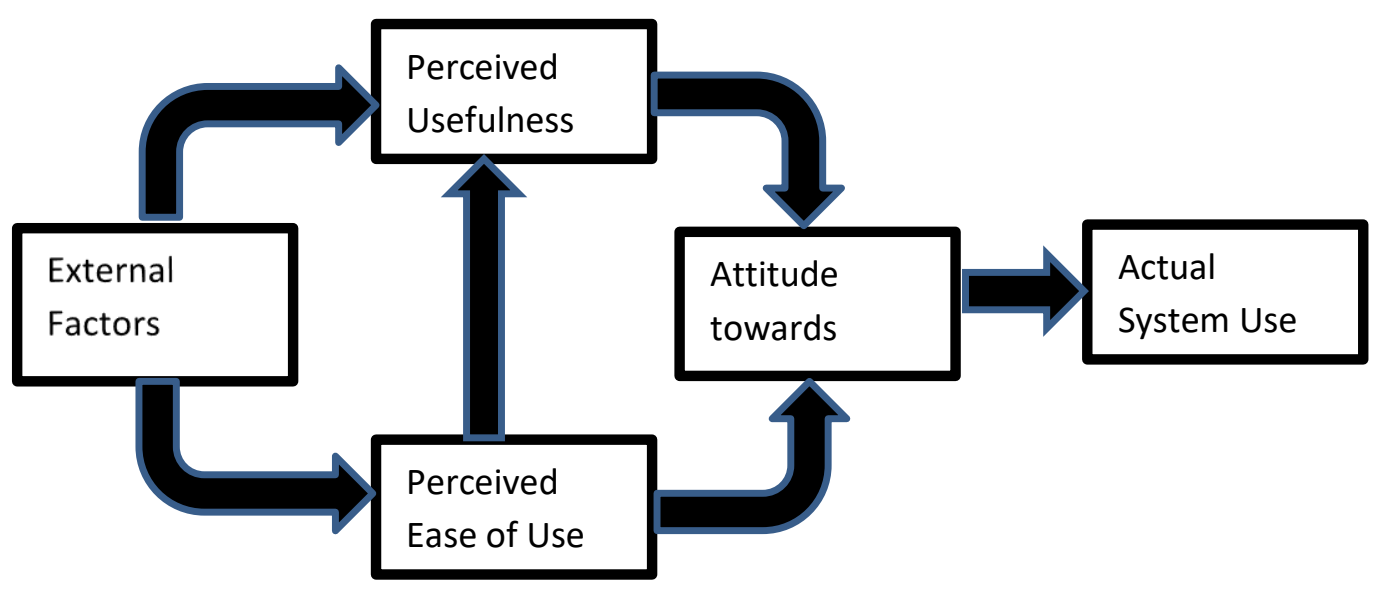

Figure 1: Technology-Acceptance Model (Davis, 1993, p. 476)

The external factors in Figure 1 refer to the external stimulus, while the perceived usefulness and the ease of use refer to the cognitive response. Attitude towards and actual system use refer to the attitudinal response and the behavioural response, respectively. 


\section{The Literature Review}

\subsection{Computer Self-Efficacy (CSE)}

Computer Self-Efficacy refers to a judgment of one's ability to use a computer (Compeau \& Higgins, 1995, p. 192), which is founded on Bandura's self-efficacy theory of behavioural change (Bandura \& Adams, 1977). Self-efficacy is indispensable for success in blended learning contexts (Shea \& Bidjerano, 2010). CSE is the belief a person has that he/she can apply computer skills in performing various computer-related tasks.

According to Compeau and Higgins (1995), a person displaying a high magnitude of CSE perceives that he/she can perform and be able to accomplish demanding computer activities; while a person with a low CSE magnitude perceives that he/she cannot. CSE strength denotes the confidence a person has to perform various activities on the computer. A person with a strong sense of CSE is highly confident, and would never be discouraged by obstacles, but continues to tackle difficult activities. On the other hand, those who display weak CSE are less confident; and they believe that they cannot do difficult activities. Lastly, selfefficacy generally, as a domain, refers to the degree to which a person believes that he/she can perform the same activities under any circumstances, when using any hardware and/or any software (Compeau \& Higgins, 1995).

\subsection{The Factors affecting computer self-efficacy}

A host of factors affect an individual's computer self-efficacy, ranging from social influence to technological influence. This study has identified six of those factors. These are namely: demographic influence, social influence, basic computer skills, access to computers, perceived usefulness and perceived ease-of-use. It was, therefore, significant for this study to examine the effects of these factors, as they affect CSE and the use of computers in turn (Compeau et al., 1999; Martinko et al., 1996). In agreement with Teo and Koh (2010), this study also considered that computer self-efficacy is a multi-dimensional construct. In this study, CSE has six constructs explained therein, the inertia of which impact computer use.

\subsubsection{The Demographic influence}

There are mixed views on the effect of gender on CSE. Findings from Teo and Koh (2010) indicate that male students demonstrated higher levels of computer selfefficacy than female students - even though the lower level of computer selfefficacy does not negatively impact female students' learning attitudes and outcome. Females' lower level of computer self-efficacy indicates positive motivation in their learning (Dang et al., 2016). In most cases, the number of the gender differences is not large (Durndell \& Haag, 2002). Therefore, studies on gender and computer self-efficacy seem to have few conclusive results on male or female experience in the use of computers. Many schools in rural and township areas in South Africa do not have any access to computers, the Internet, adequate skills, or relevant computer programs (Galpin et al., 2003; Nkula \& Krauss, 2014; Tire \& Mlitwa, 2007), which should translate into low levels of CSE. This is not always true. According to Okhakhume and Ogunlude (2016), students who displayed high CSE in their secondary education also have positive attitudes towards the use of computers. 
In a study conducted by Alahakoon (2016), involving students from 2nd and 3rdyear levels of study at the Dental Faculty, the students doing third-year level displayed high levels of computer self-efficacy. However, there is no consensus on the effects of gender, age, and computer training on CSE (Cassidy \& Eachus, 2002; Sarfo et al., 2017). In the light of the arguments in this section, it is clear that the demographic influence plays a part in pre-service teachers CSE. This study hypothesised that:

H1: The demographic influence affects an individual's perceived usefulness of a computer.

H2: The demographic influence affects an individual's computer efficacy.

H3: The demographic influence affects an individual's perceived ease of use on a computer.

\subsubsection{The social influence}

The social influence refers to how other people influence an individual's perception, beliefs, and attitudes towards using a system (Lee et al., 2021). According to Al Kurdi et al., (2020), research has shown that social influence strongly affects PU and also PEOU. A study conducted by Pontoh (2017) shows that social factors influence the use of technology, such that if social influence increases, then technology use also increases. The influence that an individual experiences from his/her colleagues motivates an individual to improve the use of technology. Hence, the following hypotheses were derived:

H4: The Social influence affects an individual's perceived usefulness of a computer;

H5: The Social influence affects an individual's computer efficacy;

H6: The Social influence affects an individual's perceived ease-of-using a computer.

\subsubsection{Basic computer skills}

Basic computer skills in this paper refer to one's ability to perform fundamental tasks on a computer. It is envisaged that these basis skills affect one's CSE. This is in tandem with the views of Cassidy and Eachus (2002), that experience with basic computer skills and the knowledge of software packages affects CSE. This view was supported by Karsten \& Roth (1998) that, there was a substantial increase in CSE for students, who were taught in an introductory computer science course compared to their counterparts, who only received verbal instruction, and who displayed no significant increase in CSE.

In support of this opinion, Magliaro and Ezeife (2007) found that computer experience was one of the major factors in predicting the computer self-efficacy scores of pre-service teachers. This study purports to validate these claims, hence the following hypotheses:

H7: Basic computer skills affect an individual's perceived usefulness with a computer;

H8: Basic computer skills affect an individual's computer self-efficacy;

H9: Basic computer skills affect an individual's perceived ease-of-use with a computer.

\subsubsection{Access to Computers}

This study also looked at whether there was a relationship between access to computers and CSE. Access to computers can be referred to as computer experience (John, 2013). Computer experience looks at how frequently the user uses a computer for different purposes, tasks, and activities. While considering 
the antecedents of computer self-efficacy, it was found that computer knowledge and previous computer experience significantly influence one's CSE (John, 2013).

The more an individual is familiar with using various computer applications, such as social-networking programs, the higher is his/her CSE (Eastin \& LaRose, 2000; John, 2013). Individuals with prior computer experience prior to using an application, display higher levels of CSE than individuals without such experience (Torkzadeh \& Koufteros, 1994). Based on these studies, the current researchers hypothesise that:

H10: Access to computers affects an individual's perceived usefulness of a computer;

H11: Access to computers affects an individual's computer self-efficacy;

H12: Access to computers affects an individual's perceived ease-of-use of a computer.

\subsubsection{Perceived Ease-of-Use}

Perceived ease-of-use is an indirect determinant of behavioural intention; and it indicates the user-friendliness of systems, which directly affects a system's usefulness (Davis, 1989). In the theoretical model, TAM, PEOU is the degree to which an individual believes that the use of a system would be free of effort. PEOU also influences PU; and they both affect CSE. He et al. (2018) stated that the perceived ease-of-use improves computer self-efficacy, which in turn affects the adoption thereof. Similarly, the current study hypothesises that:

H13: The perceived Ease-of-Use affects an individual's Perceived usefulness;

H14: The perceived Ease-of-Use affects an individual's computer self-efficacy.

\subsubsection{The perceived usefulness}

The PU is the degree to which an individual believes that the use of a system would improve his performance. An individual's feelings and behaviour have a considerable influence on the CSE (Ariff et al. (2012). Therefore, PEOU and PU are directly related to CSE (Ariff et al., 2012; Hasan, 2003; John, 2013). Consequently, the researchers postulate that:

H15: The perceived usefulness affects an individual's computer self-efficacy

\subsubsection{Computer self-efficacy}

Computer self-efficacy refers to an individual's judgment of his/her competence in operating computer applications (Muslichah, 2018). Other studies claim that computer self-efficacy is positively related to behavioural intention (Muslichah, 2018; Park, 2009). Joo et al. (2018) discovered that teacher self-efficacy has a positive influence on the intention to use technology. In another study conducted by Lew et al., (2019), the students were required to handle and design a Cloud eLearning application. The students who easily handled the flow and the design of Cloud e-Learning applications were interested in continuing to use it. The current study intends to further investigate the relationship between CSE and actual computer use. Thus, this study proposes that:

H16: Computer self-efficacy influences an individual's actual computer use.

These constructs and their hypotheses are interrelated in the proposed conceptual model in Figure 2. The model variables are: demographic influence (DI), social influence (SI), basic computer skills (CS), access to computers (AC), perceived ease-of-use (PEOU), perceived usefulness (PU), computer self-efficacy (CSE), and 
actual computer use (AU), (PU), computer self-efficacy (CSE), and actual computer use (AU).

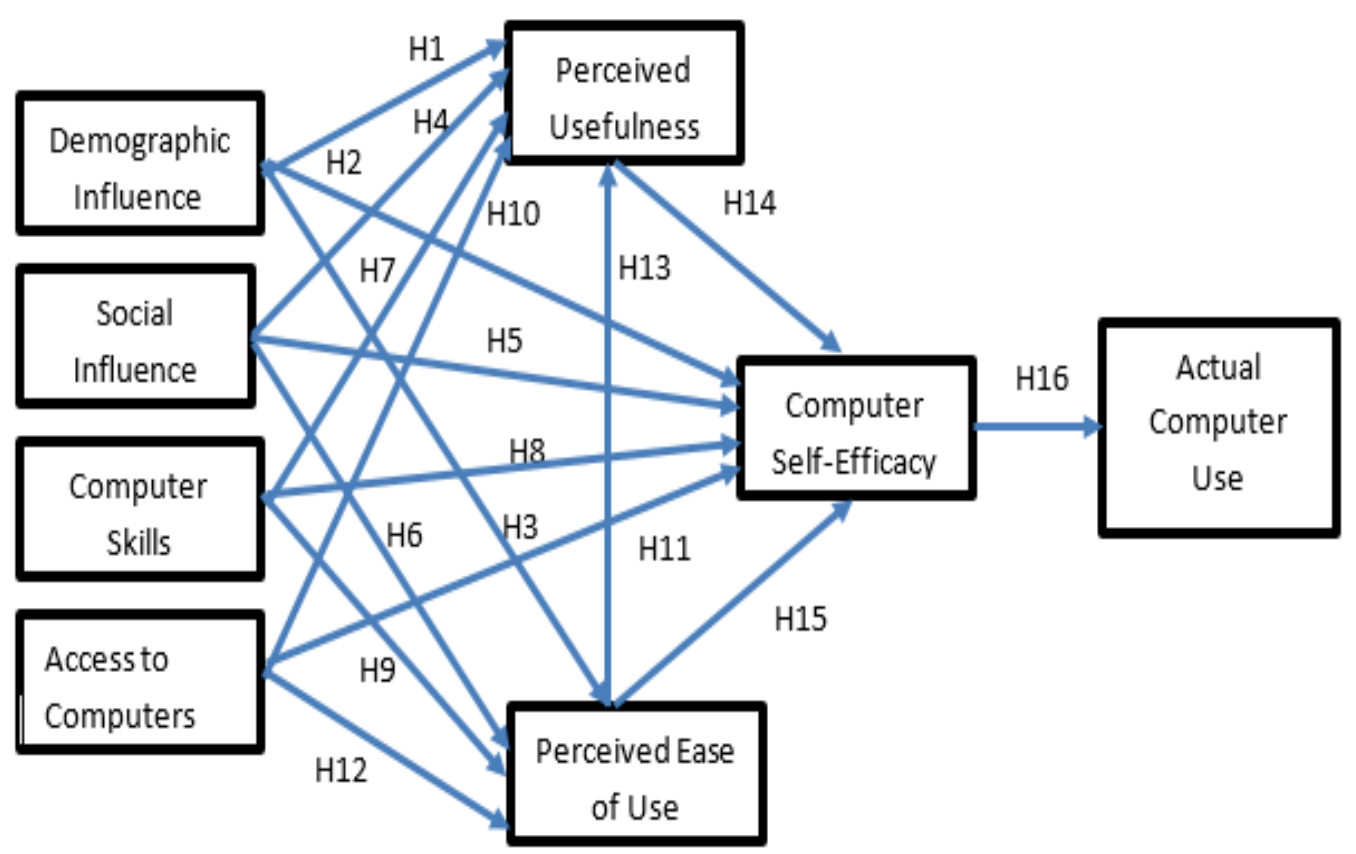

Figure 2: Computer Self-Efficacy conceptual model

\section{The Research Methodology}

This research used a quantitative design. A research design is a plan of how the researcher systematically collects and analyses the data that are needed to answer the research questions (Bertram \& Christiansen, 2014). The data were collected by using a structured five-point Likert scale questionnaire, with responses ranging from 1(strongly agree) to 5 (strongly disagree). After getting ethical clearance, consent was sought from and granted by the participants, who were informed that they had the right to voluntarily participate or withdraw from the study at any time.

The study sample of 400 participants was derived from a population of 4000 preservice teachers, according to the $10 \%$ rule, suggested by Conroy (2015). Simple random sampling was used. The instrument was then distributed to the participants. Of the 400 distributed questionnaires, 332 of them were returned successfully, yielding a respectable response rate of $83 \%$. There were 151 male and 181 female participants. Ethical procedures were observed both during and after the study, in order to honour the rights of the participants. Accordingly, we adhered to the following ethical considerations: Before the data collection, we ensured that we had obtained the participants' informed consent, while, during, and after the data collection; we protected the participants from harm and ensured their confidentiality and anonymity. Ethical clearence was issued by the Ethics Committee of the University, before the study was conducted. 


\section{Presentation and Analysis of the Results}

The results of the study are presented herewith. The Demographic profiling of the Oparticipants is presented first, followed by the measurement model, and finally the structural model. In a nutshell, the model has the following constructs: demographic influence (DI), social influence (SI), basic computer skills (CS), access to computers (AC), perceived ease-of-use (PEOU), perceived usefulness (PU), computer self-efficacy (CSE), and actual computer use (AU).

\subsection{The demographic data}

There were three items measuring the demographic data, as shown in Table 1. These items were: Gender, high-school location, and, age.

Table 1: Distribution of demographic data $(\mathrm{N}=332)$

\begin{tabular}{llcc}
\hline \multicolumn{2}{c}{ Demographic variables } & Frequency & Percent \\
\hline \multirow{2}{*}{ Gender } & Male & 151 & 45.5 \\
& Female & 181 & 54.5 \\
High-School & Urban & 16 & 4.8 \\
Location & Rural & 243 & 73.2 \\
& Informal settlement & 7 & 2.1 \\
& Township & 66 & 19.9 \\
& 17 or less & 3 & 0.9 \\
Age (in years) & $18-19$ & 98 & 29.5 \\
& $20-21$ & 92 & 27.7 \\
& $22-23$ & 81 & 24.4 \\
& 24 or more & 58 & 17.5 \\
\hline
\end{tabular}

More females (54.5\%) participated in the study than males (45.5\%). Most of the participants attended their schooling in rural areas (73.2\%). This is because the institution at which the study took place was rurally based. The participants' ages ranged from younger than 17 years to older than 24 years. The majority of them were between the ages of 18 and 19 years, and rightly so, because these were undergraduate pre-service teachers. The number of those over the age of 24 years was justified; because the institution allows a quarter of the mature entry students to attend and participate.

\subsection{The analytical technique}

To examine the proposed research model, Partial Least Squares Structural Equation Modeling (PLS-SEM) was used, as was done in previous researches (Daragmeh et al., 2021; Mutambara \& Bayaga, 2020b; Shmueli et al., 2019). PLSSEM is a good strategy for models with many latent variables, items, and hypotheses (Daragmeh et al., 2021). PLS-SEM is founded on explaining the underlying reason, and then forecasting the envisaged future behaviour (Daragmeh et al., 2021; Mutambara \& Bayaga, 2020a).

Mutambara and Bayaga (2020a) added that the primary goal of PLS-SEM is to predict the endogenous variable, in this case, computer use among pre-service teachers. The PSL-SEM was also used to evaluate the effect of pre-service teachers' demographics on their use of computers. 
The analysis followed a two-stage approach,as suggested by Hair Jr et al. (2016) that the robustness of a model is assessed through the suitability and quality of its measurement model, and then its structural model. The relationships between the latent variables and their indicators is established by the measurement model; while those among the variables are established through the analysis of the structural model (Hair Jr et al., 2016).

In the first stage, the measurement model was evaluated, in order to establish the reliability and the validity of the indicators of its many latent variables. The structural model was tested in the second stage, by examining the significance of the path coefficients, f-squared, q-squared, and, the explained variance of the endogenous variables.

\subsection{The Measurement Model}

To ascertain the measurement model, the indicator reliability, the construct reliability, the convergent validity, and the discriminant validity were assessed. The outer loadings were used to assess the indicator reliability. The results in Figure 3, show that all the outer loadings were greater than 0.7, except for CS2 (0.684), thereby confirming the indicator reliability (Hair Jr et al., 2016). Although CS2's (0.684) loading was below 0.7, it was retained, due to the exploratory nature of this study, as well as its massive contribution to content validity (Hair Jr et al., 2016). Cronbach's alpha (CA) and composite reliability (CR) were employed, in order to examine the construct reliability.

Table 2 demonstrates that the CA and the CR values are greater than the cut-off value of 0.70 , thereby confirming the construct reliability.

The average variance extracted (AVE) and the outer loadings were used to assess the convergent validity. The convergent validity measures the extent to which there is a high connection between the theoretically identical constructs (Mutambara \& Bayaga, 2020a). All the outer loadings were significant at the 5\% level of significance; since they were all above 0.7 (Hair Jr et al., 2016).

The results in Table 1 show that all the AVEs were greater than the threshold value of 0.5. The results of this study confirmed the measurement model's convergent validity; as the AVEs were greater than 0.5, and the outer loadings were significant at the $5 \%$ level of significance.

According to Hair Jr et al. (2016), discriminant validity measures the extent to which a latent variable differs from other latent variables in the model. The Fornell-Larcker's criterion was used to assess the discriminant validity. The latent variable should share more variance with its assigned indicators than with any other latent variable (Hair Jr et al., 2016). Therefore, the square root of the average variance extracted should be larger than its correlation with any other latent variable. In Table 1, the numbers in bold are larger than any other value in each column, indicating thereby that each latent variable shared more variance with its indicators. The results confirmed the discriminant validity. 
Table 2: The measurement model

\begin{tabular}{lllllllllllll}
\hline \multicolumn{1}{l}{ Construct } & CA & CR & AVE & AC & AU & CS & CSE & DI_ & PEOU & PU & SI \\
\hline AC & 0.846 & 0.897 & 0.684 & $\mathbf{0 . 8 2 7}$ & & & & & & & \\
AU & 0.863 & 0.900 & 0.644 & 0.577 & $\mathbf{0 . 8 0 3}$ & & & & & & \\
CS & 0.735 & 0.829 & 0.549 & 0.250 & 0.436 & $\mathbf{0 . 7 4 1}$ & & & & & \\
CSE & 0.899 & 0.925 & 0.712 & 0.439 & 0.778 & 0.527 & $\mathbf{0 . 8 4 4}$ & & & & \\
DI_ & 0.830 & 0.873 & 0.580 & 0.091 & 0.245 & 0.462 & 0.370 & $\mathbf{0 . 7 6 2}$ & & & \\
PEOU & 0.817 & 0.872 & 0.578 & 0.777 & 0.612 & 0.389 & 0.562 & 0.185 & $\mathbf{0 . 7 6 0}$ & & \\
PU & 0.804 & 0.872 & 0.631 & 0.385 & 0.580 & 0.583 & 0.596 & 0.279 & 0.486 & $\mathbf{0 . 7 9 4}$ & \\
SI & 0.877 & 0.915 & 0.730 & 0.446 & 0.788 & 0.512 & 0.825 & 0.252 & 0.552 & 0.548 & $\mathbf{0 . 8 5 5}$ \\
\hline
\end{tabular}

Note: $\mathrm{CA}=$ Cronbach's alpha, $\mathrm{CR}=$ convergent reliability, $\mathrm{AVE}=$ average variance extracted, while $\mathrm{AC}=$ Access to computers, $\mathrm{AU}=$ Actual computer use, $\mathrm{CS}=$ Basic computer skills, $\mathrm{CSE}=$ Computer self-efficacy, $\mathrm{DI}_{-}=$Demographic influence, $\mathrm{PU}=$ perceived usefulness, $\mathrm{PEU}=$ perceived ease-of-use, $\mathrm{SI}=$ Social influence .

\subsection{The Structural Model}

After confirming the measurement model's reliability and validity, the next stage was to evaluate the structural model. To assess the collinearity issues, the variance inflation-factor values (VIF) were used. The results in Table 2 show that all the VIFs were less than 4, thereby indicating the absence of collinearity among the latent variables. To assess the significance of the standardised path coefficients, representing the hypotheses depicted in Figure 1, a full bootstrapping procedure with (5000 replicate samples) was used (Hair Jr et al., 2016). The $\mathrm{R}^{2}, \mathrm{f}^{2}, \mathrm{Q}^{2}$ and the path coefficients were used to assess the structural model.

According to Chin (1998), the $\mathrm{R}^{2}$ values of $0.19,0.33$ and 0.67 are considered to be "weak"," moderate" and "substantial", respectively. The results in Figure 2 show that the $\mathrm{R}^{2}$ values of PEOU, PU, CSE, and AU were 0.665, 0.454, 0.737, and 0.606, respectively. The results show that the $\mathrm{R}^{2}$ value of CSE is considered substantial, while those of PEOU, PU, and AU are considered moderate. Using the blindfolding method, the results show that the $\mathrm{Q}^{2}$ values for PEOU (0.379), PU (0.279), AU (0.378), and CSE (0.514) are all greater than zero, confirming the predictive validity of the structural model. These results imply that the DI, SI, CS, and AC together explain $66.5 \%$ of the variance in PEOU and $45.4 \%$ of the variance in PU. A substantial amount of variance of $73.7 \%$ is explained in CSE by PU, PEOU, DI, SI, CS, and AC. All the model's exogenous variables explained $60.6 \%$ of the variance in AU.

Table 3: Path coefficients, $\mathrm{f}^{2}$, and VIF

\begin{tabular}{lcccccc}
\hline Path & Std Beta & T Statistics & P Values & Decision & $\mathrm{f}^{2}$ & VIF \\
\hline AC -> CSE & $-0,004$ & 0,069 & 0,945 & Rejected & $0.000^{\mathrm{a}}$ & 2,543 \\
AC -> PEOU & 0,656 & 15,758 & 0,000 & Accepted & $1.029 \mathrm{c}$ & 1,251 \\
AC -> PU & 0,059 & 0,762 & 0,446 & Accepted & $0.003^{\mathrm{a}}$ & 2,537 \\
CS -> CSE & 0,000 & 0,007 & 0,995 & Rejected & $0.000^{\mathrm{a}}$ & 1,920 \\
CS -> PEOU & 0,113 & 2,335 & 0,020 & Accepted & $0.024^{\mathrm{a}}$ & 1,617 \\
CS -> PU & 0,380 & 6,585 & 0,000 & Accepted & $0.160^{\mathrm{b}}$ & 1,655 \\
CSE -> AU & 0,778 & 32,875 & 0,000 & Accepted & $1.536^{\mathrm{c}}$ & 1,000 \\
DI_-> CSE & 0,146 & 5,013 & 0,000 & Accepted & $0.063^{\mathrm{a}}$ & 1,276
\end{tabular}




\begin{tabular}{lcccccc} 
DI_-> PEOU & 0,024 & 0,650 & 0,516 & Rejected & $0.001^{\mathrm{a}}$ & 1,274 \\
DI_-> PU & 0,009 & 0,227 & 0,821 & Rejected & $0.000^{\mathrm{a}}$ & 1,276 \\
PEOU -> CSE & 0,108 & 1,911 & 0,056 & Rejected & $0.015^{\mathrm{a}}$ & 3,035 \\
PEOU -> PU & 0,162 & 2,037 & 0,042 & Accepted & $0.016^{\mathrm{a}}$ & 2,987 \\
PU -> CSE & 0,149 & 2,965 & 0,003 & Accepted & $0.046^{\mathrm{a}}$ & 1,833 \\
SI -> CSE & 0,648 & 17,231 & 0,000 & Accepted & $0.887^{\mathrm{c}}$ & 1,804 \\
SI -> PEOU & 0,196 & 3,702 & 0,000 & Accepted & $0.073^{\mathrm{a}}$ & 1,587 \\
SI -> PU & 0,235 & 3,960 & 0,000 & Accepted & $0.060^{\mathrm{a}}$ & 1,702 \\
\hline
\end{tabular}

Note: $\mathrm{AC}=$ Access to computers, $\mathrm{AU}=$ Computer use, $\mathrm{CS}=$ Computer skills, $\mathrm{CSE}=$ Computer self-efficacy, DI_ = Demographic Influence, $\mathrm{PU}=$ perceived usefulness, $\mathrm{PEOU}$ $=$ perceived ease of use, $\mathrm{SI}=$ Social Influence, $\mathrm{a}=$ small effect, $\mathrm{b}=$ moderate effect, , and $\mathrm{c}=$ large effect

The empirical model in Figure 3 shows all the latent variables, together with their indicators. All the indicators load well, except CS2 (0.684); but it was retained; since it adds significant positive influence on both PEOU and PU (see the measurement model). None of the four explanatory variables were rejected outright. Hence, they remain in the model.

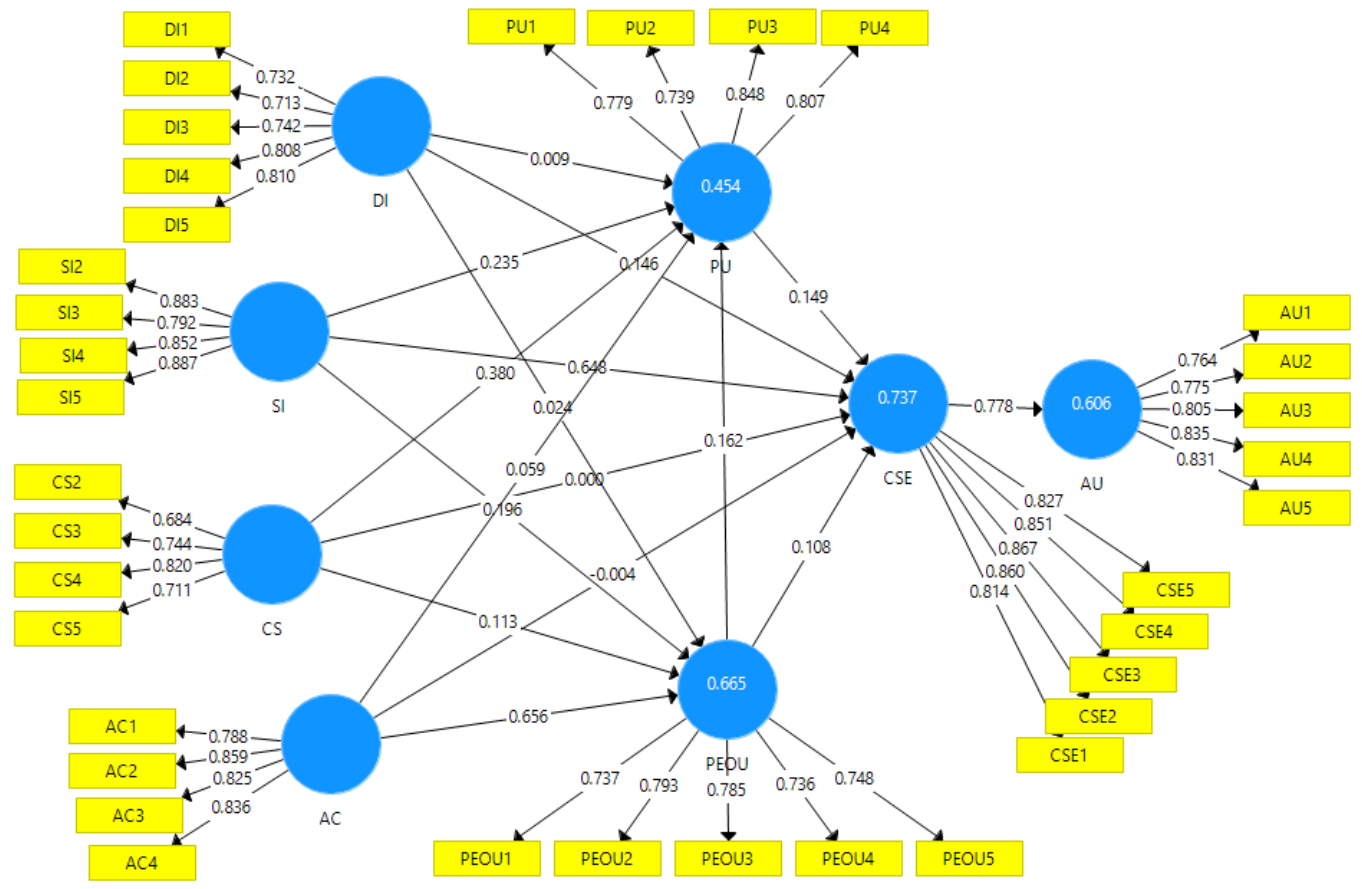

Figure 3: The empirical model

The results showed that access to computers has a significant effect on the perceived ease-of-use and on the perceived usefulness $(\beta=0.656, t$-value 15.758 , $\mathrm{p}<0.05$ and $\beta=0.059, \mathrm{t}-\mathrm{v}$ alue $0.762, \mathrm{p}>0.05$, respectively $)$, but not on CSE $(\beta=-0.004$, $\mathrm{t}$-value $0.069, \mathrm{p}>0.05)$. The results also showed that computer skills have a significant effect on the perceived ease-of-use and the perceived usefulness ( $\beta=0.113$, $t$-value 2.335, $p<0.05$, and $\beta=0.380$, $t$-value 6.585, $p<0.05$, respectively), but not on CSE $(\beta=0.000, t$-value $0.007, p>0.05)$. Computer self-efficacy has a significant effect on the actual use $(\beta=0.778$, $t$-value $32.875, p<0.05)$. 
The demographic influence does not have a statistically significant effect on the perceived usefulness and the perceived ease-of-use $(\beta=0.009$, t-value $0.227, p>0.05$ and $\beta=0.024, t$-value $0.650, p>0.05$ respectively), but on computer self-efficacy $(\beta=0.146$, $t$-value 5.013, $p<0.05)$. Perceived ease-of-use does not have a significant effect on computer self-efficacy $(\beta=0.108$, $t$-value $1.911, p>0.05)$, but rather on perceived usefulness $((\beta=0.162, \mathrm{t}$-value 2.037, $\mathrm{p}<0.05)$. The results also showed that perceived usefulness has a significant effect on computer self-efficacy $(\beta=0.149$, t-value 2.965, $p>0.05)$. Social influence has a significant effect on computer self-efficacy, perceived ease-of-use, and perceived usefulness $(\beta=0.648$, $\mathrm{t}$-value 17.231, $\mathrm{p}<0.05, \beta=0.196$, $\mathrm{t}$-value 3.702, $\mathrm{p}<0.05$, and $\beta=0.235$, $\mathrm{t}$-value 3.960, $\mathrm{p}<0.05$, respectively).

The $\mathrm{f}^{2}$ measures the strength of the relationship between the constructs. According to Cohen (1988), the $\mathrm{f}^{2}$ values of $0.35,0.15$, and 0.02 indicate high, medium, and low levels of effect size, respectively. In this study, the results show that three of the sixteen hypotheses had a high effect on CSE; but only one hypothesis had a medium effect; while the rest had a low effect on CSE.

\subsection{The moderating effect of demographics}

The bootstrapping procedure with 5000 subsamples was used to test for the significance of the moderation effect of demographic items, high-school location, age, and gender, on the relationship between computer self-efficacy and computer use. The results are shown in Table 3 and in Figure 2. These results show that age $(\beta=-0.068, \mathrm{t}$-value $=1.762, \mathrm{p}>0.05)$, high-school location $(\beta=0.017, \mathrm{t}$-value $=$ $0.346, p>0.05)$, and gender $(\beta=0.030$, $t$-value $=0.652, p>0.05)$ do not have any significant effect on these relationships Age-CSE-AU $\rightarrow>$ AU, Gender-CSE-AU -> AU, and High School Location-CSE-AU ->AU.

Table 4: The moderating effect

\begin{tabular}{lcccl}
\hline \multirow{2}{*}{ Paths } & Std & $\mathrm{T}$ & $\mathrm{P}$ & Decision \\
& Beta & Statistics & Values & \\
\hline Age -> AU & -0.015 & 0.433 & 0.665 & Rejected \\
Age-CSE-AU -> AU & -0.068 & 1.762 & 0.078 & Rejected \\
CSE -> AU & 0.781 & 32.976 & 0.000 & Accepted \\
Gender -> AU & -0.007 & 0.210 & 0.834 & Rejected \\
Gender-CSE-AU -> AU & 0.030 & 0.652 & 0.515 & Rejected \\
High School Location -> AU & 0.010 & 0.295 & 0.768 & Rejected \\
High School Location-CSE-AU -> & 0.017 & 0.346 & 0.729 & Rejected \\
AU & & & & \\
\hline
\end{tabular}




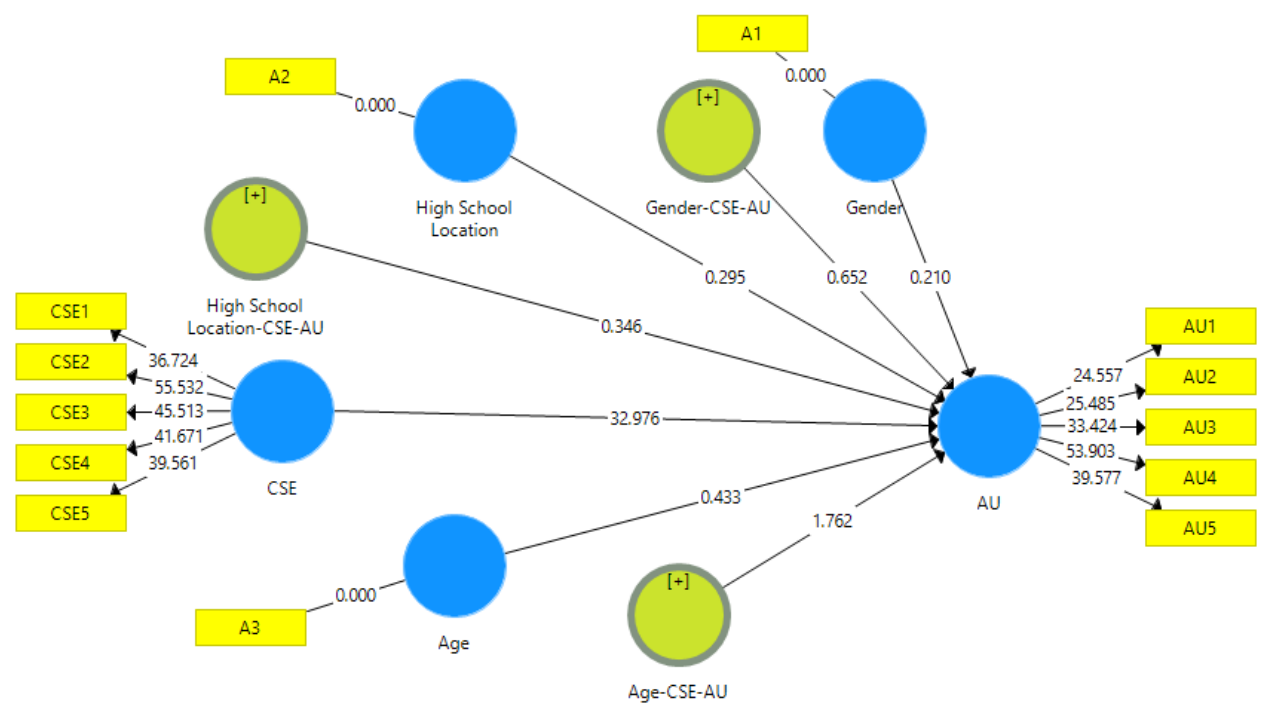

Figure 4: Moderation effect of demographic items

\section{Discussion}

The purpose of this study was to examine the effects of pre-service teachers' computer self-efficacy on their use of computers. The following research questions were asked:

RQ1: What are the determinants of pre-service teachers Computer Self-Efficacy?

RQ2: What is the effect of pre-service teachers' Computer Self-Efficacy on their computer use?

RQ3: Is there any relationship between pre-service teachers' demographics and their use of computers?

In the analysis of this research, there were mixed results. Ten of the hypotheses were accepted, while six of them were rejected. However, this did not result in any of the constructs being rejected outright. Instead, the remaining hypotheses effectively anchored the model.

RQ1: This question aimed to find the determinants of the pre-service teachers' computer self-efficacy. The researchers envisaged that there are six factors that seek to determine pre-service teachers' computer self-efficacy. These are namely: demographic influence (DI), social influence (SI), basic computer skills (CS), access to computers (AC), perceived ease-of-use (PEOU), perceived usefulness (PU), computer self-efficacy (CSE), and actual computer use (AU). These factors altogether explain $73.5 \%$ of the variance in CSE. This means that only $26.5 \%$ of the factors affecting CSE are not explained by the model.

It was also interesting to note that the external variables explained $66.5 \%$ of the variance in PEOU and $45.4 \%$ of the variance in PU, where both PEOU and PU were integral factors affecting CSE. Interestingly, the perceived ease-of-use does not have a significant effect on computer self-efficacy $(\beta=0.108$, $t$-value 1.911 , $p>0.05)$, but rather on the perceived usefulness $(\beta=0.162$, $t$-value 2.037, $p<0.05)$. Contrary to the findings of this study, the perceived ease-of-use improves computer self-efficacy, which in turn affects the adoption (He et al., 2018). The results also showed that perceived usefulness has a significant effect on computer self-efficacy $(\beta=0.149$, $t$-value $2.965, \mathrm{p}>0.05)$. 
In support of this finding, Ariff et al., 2012; Hasan, 2003; John, (2013) found that an individual's perceptions have a great influence on CSE; and consedquently, PEOU and PU are directly related to CSE.

The analysis also established that access to computers has a significant effect on perceived ease-of-use $(\beta=0.656, \mathrm{t}$-value 15.758, $\mathrm{p}<0.05)$ and on the perceived usefulness $(\beta=0.059, \mathrm{t}$-value $0.762, \mathrm{p}>0.05)$. This is supported by the results in a study conducted by John (2013), who found that access to computers has a significant influence one's computer self-efficacy. This study, however, found that access to computers does not necessarily influence computer self-efficacy ( $\beta=$ 0.004, t-value 0.069, p>0.05).

The results also showed that computer skills have a significant effect on perceived ease-of-use and perceived usefulness $(\beta=0.113$, t-value 2.335, $p<0.05$, and $\beta=0.380$, $\mathrm{t}$-value $6.585, \mathrm{p}<0.05$, respectively). The results also showed that one's computer skills have no influence on CSE $(\beta=0.000$, $t$-value $0.007, p>0.05)$. These results are a direct opposite of the results of Magliaro and Ezeife (2007), who found that computer skills (CS) was one of the major factors in predicting the computer selfefficacy scores of pre-service teachers.

However, (Karsten \& Roth, 1998) contradicted this notion in that there was a substantial increase in CSE for students, who had been taught in an introductory computer-science course.

The demographic Influence in this study does not have a statistically significant effect on the perceived usefulness and the perceived ease-of-use $(\beta=0.009$, $t$-value $0.227, p>0.05$ and $\beta=0.024$, $t$-value $0.650, p>0.05$ respectively). The results also show that the demographic influence has a statistically significant effect on computer self-efficacy $(\beta=0.146$, $t$-value 5.013, $\mathrm{p}<0.05)$. These results look conclusive, that demographic influence affects computer self-efficacy significantly.

However, there are mixed views on the effect of gender on computer self-efficacy. The findings of Teo and Koh (2010) indicate that male students demonstrated higher computer self-efficacy than female students. Other studies also claim that there is no consensus on the effects of gender, age, and computer training on computer self-efficacy (Cassidy \& Eachus, 2002; Sarfo et al., 2017). Research on gender and computer self-efficacy, therefore, seem not to have any conclusive results on male or female experience and on their use of computers.

Social Influence has a significant effect on computer self-efficacy, perceived easeof-use, and perceived usefulness $(\beta=0.648$, t-value 17.231, $p<0.05, \beta=0.196$, $t$-value $3.702, \mathrm{p}<0.05$, and $\beta=0.235$, $\mathrm{t}$-value 3.960, $\mathrm{p}<0.05$, respectively). These findings are consistent with those of the previous studies, which reported that social influence strongly affects PU and also PEOU (Al Kurdi et al., 2020); and that if social influence increases, then technology use also increases (Pontoh, 2017).

RQ2: To measure the effect of pre-service teachers' computer self-efficacy on their computer use, H16 was calculated. The results showed that computer self-efficacy 
has a significant impact on actual use $(\beta=0.778, t$-value $32.875, \mathrm{p}<0.05)$. Other researchers support these results. Muslichah (2018) found that computer selfefficacy is positively related to behavioural intention; while Joo et al. (2018) discovered that teacher self-efficacy had a positive influence on their intention to use technology. The same support was found from a study conducted by Lew et al. (2019). They concluded that students who easily manipulated flow and design of Cloud e-Learning application, were interested in continuing to use it.

RQ3: To find the relationship between pre-service teachers' demographics and their use of computers, the moderating effects of demographics were used. All three moderators in Table 4 were rejected, implying that the demographic variables do not have a significant effect on the relationship CSE and AU. This means that pre-service teachers' background information does not influence their eventual use of computers. These findings were supported by (Sarfo et al., 2017), who found that there were no differences in computer self-efficacy between teachers of 20-30 years and those of 31 years and above. This implies that the age of the teachers does not influence their computer self-efficacy. These findings are contrary to the claim by (Muslichah 2018) that computer self-efficacy is positively related to behavioural intention.

In another study, Simsek (2011) suggested that male and female students are more pragmatic so that there may not be differences between genders in terms of computers. Hence, both males and females have similar computer selfefficacy. The raging debate about the effects of demographics as moderators remains unresolved. Recently, it has been suggested that contemporary male and female students alike are more pragmatic so that there may not be differences between genders and generalisations in terms of computers. The important aspect in the findings is that computer self-efficacy has a significant effect on the actual use. This study proposes that computer self-efficacy influences actual computer use. These findings imply that pre-service teachers with high computer selfefficacy would use a computer more than the those with low computer selfefficacy. Based on this finding, the institution under study must create an environment that enhances pre-service teacher's computer self-efficacy. It can be suggested that if more pre-service teachers engage with computers; then more of them would interact with e-learning resources and services.

Hence, each of these constructs has a significant effect on computer self-efficacy: access to computers, demographic influence, social influence, and perceived usefulness. Access to computers implies that a student had a prior experience in computer use. A student working with computers over some years, gains experience in the use of computers, which influences his attitude towards computers and ultimately his computer self-efficacy (Hatlevik et al., 2018). Social influence as a predictor of adoption implies that a student's friends, lecturers, parents, officials can influence him towards the use of computers, and hence positively influence intention to use computers (Joe et al., 2020). It is therefore imperative for the institution to regularly organise computer workshops, presentations, seminars on the use of computers for pre-service teachers. 
The study draws a relationship between perceived usefulness and self-efficacy in the use of the computer. If pre-service teachers display a positive perception of computer self-efficacy, they will regard the use of computers as easy to operate (Thongsri et al., 2020). It is therefore incumbent upon administrators, lecturers and programme designers to develop simple computer systems that focus on ease of use, in order to attract pre-service teachers.

\section{Conclusions}

The study employed the Technology-Acceptance Model to examine the effects of pre-service teachers' computer self-efficacy on their use of computers. Factor analysis was used to analyse the data generated from the survey with the help of the SmartPLS software. Findings of the study indicated that each of the identified factors in the model has a significant effect on computer self-efficacy. In essence, the identified eight factors explained $73.7 \%$ of the variance in computer selfefficacy. The four independent variables explained $45.4 \%$ of the variance in the perceived usefulness of computers and $66.5 \%$ of the variance in perceived easeof-use of the use of computers.

The computer self-efficacy model also explained an impressive $60.6 \%$ of the variance in computer use. The research concludes that the factors identified in the model were highly relevant. It was also established that the model was robust and stable.

Understanding pre-service teachers' computer self-efficacy is a complex challenge. This is so true in a university setting, where pre-service teachers are expected to conduct their teaching and learning activities through the use of computers, but with limited resources. The challenge arises because most lecturers are qualified as subject specialists and not as computer practitioners. It is therefore important to understand the factors that affect computer self-efficacy.

\section{Recommendations and Limitations}

\subsection{Implications for Students}

Pre-service teachers rely on other students, friends, or colleagues when they encounter computer-related problems, which does not help much to improve preservice teachers' computer self-efficacy. The computer centre administrators should set up a student-assistant team to help those that encounter problems.

\subsection{Implications for lecturers}

All academic and support staff should receive regular computer training relevant to their academic activities, which are expected to enhance pre-service teachers' computer self-efficacy.

\subsection{Implications for University Administrators}

It can be recommended that higher education institutions ascertain that all students have access to computers, connectivity, and skilled technicians. This creates a degree of confidence required for students to develop a strong computer self-efficacy. 


\subsection{Limitations}

A major limitation of this study was its population, which consisted of the faculty of education students in the institution under study. This included participants from other faculties of the institution and other universities, who could have helped to validate the results of the study.

\section{References}

Al Kurdi, B., Alshurideh, M., Salloum, S., Obeidat, Z., \& Al-dweeri, R. (2020). An empirical investigation into examination of factors influencing university students' behavior towards elearning acceptance using SEM approach. International Journal of Interactive Mobile Technologies (iJIM), 14(2), 19-41. https://doi.org/10.3991/ijim.v14i02.11115

Alahakoon, C. N. (2016). Impact of computer self-efficacy and computer anxiety: a practical indicator of dental students' computer competency in Sri Lanka. Journal of the University Librarians Association of Sri Lanka, 19(2). https://doi.org/10.4038/jula.v19i2.7886

Ariff, M. S. M., Yeow, S., Zakuan, N., Jusoh, A., \& Bahari, A. Z. (2012). The effects of computer self-efficacy and technology acceptance model on behavioral intention in internet banking systems. Procedia-Social and Behavioral Sciences, 57, 448-452. https:// doi.org/10.1016/j.sbspro.2012.09.1210

Bertram, C., \& Christiansen, I. (2014). Understanding research: An introduction to reading research. Van Schaik.

Cassidy, S., \& Eachus, P. (2002). Developing the computer user self-efficacy (CUSE) scale: Investigating the relationship between computer self-efficacy, gender and experience with computers. Journal of Educational Computing Research, 26(2), 133153. https://doi.org/10.2190/JGJR-0KVL-HRF7-GCNV

Chin, W. W. (1998). The partial least squares approach to structural equation modeling. Modern methods for business research, 295(2), 295-336. https:/ /scholar.google.co.za/scholar?hl=en\&as_sdt=0\%2C5\&q=Chin\%2C+W.+ W.+\%28Ed.\%29.+\%281998\%29.+The+Partial+Least+Squares+approach+for+stru ctural+equation+modelling.+Hillsdale $\% 2 \mathrm{C}+\mathrm{New}+$ Jersey $\% 3 \mathrm{~A}+$ Lawrence+Erlbau $\mathrm{m}+$ Associates\&btnG $=$

Cohen, J. (1988). Statistical power analysis for the behavioral sciences. Lawrence Erlbaum Associates. Hillsdale, NJ, 20-26.

Compeau, D. R., \& Higgins, C. A. (1995). Computer self-efficacy: Development of a measure and initial test. MIS quarterly, 189-211. https://doi.org/10.2307/249688

Dang, Y., Zhang, Y., Ravindran, S., \& Osmonbekov, T. (2016). Examining student satisfaction and gender differences in technology-supported, blended learning. Journal of Information Systems Education, 27(2), 119-130. http://jise.org/volume27/n2/JISEv27n2p119.html

Daragmeh, A., Sági, J., \& Zéman, Z. (2021). Continuous Intention to Use E-Wallet in the Context of the COVID-19 Pandemic: Integrating the Health Belief Model (HBM) and Technology Continuous Theory (TCT). Journal of Open Innovation: Technology, Market, and Complexity, 7(2), 132. https://doi.org/10.3390/joitmc7020132

Davis, F. D. (1993). User acceptance of information technology: system characteristics, user perceptions and behavioral impacts. International journal of man-machine studies, 38(3), 475-487. https://doi.org/10.1006/imms.1993.1022

Durndell, A., \& Haag, Z. (2002). Computer self efficacy, computer anxiety, attitudes towards the Internet and reported experience with the Internet, by gender, in an East European sample. Computers in Human Behavior, 18(5), 521-535. https://doi.org/10.1016/S0747-5632(02)00006-7 
Galpin, V., Sanders, I., Turner, H., \& Venter, B. (2003). Computer self-efficacy, gender, and educational background in South Africa. IEEE Technology and Society Magazine, 22(3), 43-48. https://doi.org/10.1109/MTAS.2003.1237471

Hair Jr, J. F., Hult, G. T. M., Ringle, C., \& Sarstedt, M. (2016). A primer on partial least squares structural equation modeling (PLS-SEM). Sage publications.

Hasan, B. (2003). The influence of specific computer experiences on computer self-efficacy beliefs. Computers in Human Behavior, 19(4), 443-450. https:// doi.org/10.1016/S0747-5632(02)00079-1

Hatlevik, O. E., Throndsen, I., Loi, M., \& Gudmundsdottir, G. B. (2018). Students' ICT selfefficacy and computer and information literacy: Determinants and relationships. $\begin{array}{lllll}\text { Computers } \mathcal{E} \quad \text { Education, 118, } & \text { 107-119. }\end{array}$ https://doi.org/10.1016/j.compedu.2017.11.011

Hauser, R., Paul, R., \& Bradley, J. (2012). Computer self-efficacy, anxiety, and learning in online versus face to face medium. Journal of Information Technology Education: Research, 11(1), 141-154. https://doi.org/10.28945/1633

He, Y., Chen, Q., \& Kitkuakul, S. (2018). Regulatory focus and technology acceptance: Perceived ease of use and usefulness as efficacy. Cogent Business $\mathcal{E}$ Management, 5(1), 1459006. https://doi.org/10.1080/23311975.2018.1459006

Hueros, D., María, A., \& Arteaga Sánchez, R. (2010). Motivational factors that influence the acceptance of Moodle using TAM. https://doi.org/10.1080/15256480.2020.1746217

Joe, S., Kim, J., \& Zemke, D. M. V. (2020). Effects of social influence and perceived enjoyment on Kiosk acceptance: a moderating role of gender. International Journal of Hospitality $\& \quad$ Tourism Administration, 1-28. https://doi.org/10.1080/15256480.2020.1746217

John, S. P. (2013). Influence of computer self-efficacy on information technology adoption. International Journal of Information Technology, 19(1), 1-13. http://www.intjit.org/cms/journal/volume/19/1/191_2.pdf

Joo, Y. J., Park, S., \& Lim, E. (2018). Factors influencing preservice teachers' intention to use technology: TPACK, teacher self-efficacy, and technology acceptance model. Journal of Educational Technology \& Society, 21(3), 48-59. https://www.jstor.org/stable/26458506?seq=1\#metadata_info_tab_contents

Karsten, R., \& Roth, R. M. (1998). Computer self-efficacy: A practical indicator of student computer competency in introductory IS courses. Informing Science, 1(3), 61-68. https://doi.org/10.28945/615

Lee, J., Erdogan, A. N., \& Hong, I. B. (2021). Participation in the Sharing Economy Revisited: The Role of Culture and Social Influence on Airbnb. Sustainability, 13(17), 9980. https:// doi.org/10.3390/su13179980

Lew, S.-L., Lau, S.-H., \& Leow, M.-C. (2019). Usability factors predicting continuance of intention to use cloud e-learning application. Heliyon, 5(6), e01788. https://doi.org/10.1016/j.heliyon.2019.e01788

Magliaro, J., \& Ezeife, A. N. (2007). Pre-service teachers' preparedness to integrate computer technology into the curriculum. Canadian Journal of Learning and Technology, 33(3), 95. https://doi.org/10.21432/T2TP4V

Muslichah, M. (2018). The effect of self efficacy and information quality on behavioral intention with perceived usefulness as intervening variable. Journal of Accounting, Business and Management (JABM), 25(1), 21-34. https://doi.org/10.31966/jabminternational.v1i25.327

Mutambara, D., \& Bayaga, A. (2020a). Rural-based Science, Technology, Engineering and Mathematics teachers' and learners' acceptance of mobile learning. SA Journal of Information Management, 22(1), 10. https:// doi.org/10.4102/sajim.v22i1.1200 
Mutambara, D., \& Bayaga, A. (2020b). Understanding Rural Parents' Behavioral Intention to Allow Their Children to Use Mobile Learning. Conference on e-Business, eServices and e-Society, https://doi.org/10.1007/978-3-030-44999-5_43

Nkula, K., \& Krauss, K. E. (2014). The integration of ICTs in marginalized schools in South Africa: Considerations for understanding the perceptions of in-service teachers and the role of training. International Development Informatics Association (IDIA) conference, https://web.archive.org/web/20180504094930id_/http://www.developmentin formatics.org/conferences/2014/papers/20-Nkula-Kirsten.pdf

Okhakhume, A. S., \& Ogunlude, F. B. (2016). Socio-Demographic Characteristics and Perceived Computer Self-Efficacy as Determinants of Attitudes Towards Computer Use Among Secondary School Students. Landmark Research Journals of Medicine and Medical Sciences, 3(7), 070-078

Park, S. Y. (2009). An analysis of the technology acceptance model in understanding university students' behavioral intention to use e-learning. Journal of Educational $\begin{array}{lllll}\text { Technology } & \mathcal{E} & \text { Society, } & 12(3), & 150-162 .\end{array}$ https://www.jstor.org/stable/pdf/jeductechsoci.12.3.150.pdf

Pontoh, G. T. (2017). The influence of technology acceptance, social influence, faciliatating condition, and computer self-efficacy on e-office utilization in immigration office class I Makassar. The Business \& Management Review, 9(2), 213-218. https://cberuk.com/cdn/conference_proceedings/conference_97448.pdf

Sarfo, F. K., Amankwah, F., \& Konin, D. (2017). Computer Self-Efficacy among Senior High School Teachers in Ghana and the Functionality of Demographic Variables on Their Computer Self-Efficacy. Turkish Online Journal of Educational TechnologyTOJET, 16(1), 19-31. https:/ / files.eric.ed.gov/fulltext/EJ1124909.pdf

Shmueli, G., Sarstedt, M., Hair, J. F., Cheah, J.-H., Ting, H., Vaithilingam, S., \& Ringle, C. M. (2019). Predictive model assessment in PLS-SEM: guidelines for using PLSpredict. European Journal of Marketing. https://doi.org/10.1108/EJM-02-20190189

Simsek, A. (2011). The relationship between computer anxiety and computer self-efficacy. Contemporary educational technology, 2(3), 177-187. https://doi.org/10.30935/cedtech/6052

Teo, T., \& Koh, J. H. L. (2010). Assessing the dimensionality of computer self-efficacy among pre-service teachers in Singapore: a structural equation modeling approach. International Journal of Education and Development using ICT, 6(3), 7-18. https://doi.org/10.3860/taper.v18i1.1035

Thongsri, N., Shen, L., \& Bao, Y. (2020). Investigating academic major differences in perception of computer self-efficacy and intention toward e-learning adoption in China. Innovations in Education and Teaching International, 57(5), 577-589. https://doi.org/10.1080/14703297.2019.1585904

Tire, T., \& Mlitwa, N. (2007). ICT access and use in rural schools in South Africa: The Northern Cape Province. Faculty of Informatics and Design, Cape Peninsula University of Technology. https://www.researchgate.net/publication/266176515 


\section{Appendix 1}

\section{Pre-service teachers' computer self-efficacy and the use of computers}

\section{Purpose of the study}

The purpose of this study is to examine the effects of preservice teachers' computer self-efficacy in their use of computers. The data gathered from this survey will be used solely for this purpose. To aid the study, will you please answer the following questions. Participation in this survey is by choice, you can opt out at any time you feel like doing so. Your individual responses to the survey will be strictly confidential.

\section{Section A: Demographic data}

(Please tick the appropriate box)

\section{Gender}

\begin{tabular}{|l|l|}
\hline Male & Female \\
\hline 1 & 2 \\
\hline
\end{tabular}

\section{High School Location}

\begin{tabular}{|l|l|l|l|}
\hline Urban & Rural & Informal settlement & Township \\
\hline 1 & 2 & 3 & 4 \\
\hline
\end{tabular}

\section{Age (in years)}

\begin{tabular}{|l|l|l|l|l|}
\hline$\leq 17$ & $18-19$ & $20-21$ & $22-23$ & $\geq 24$ \\
\hline 1 & 2 & 3 & 4 & 5 \\
\hline
\end{tabular}

\section{Section B: Constructs and indicators}

Please indicate your level of agreement with each of the following statements by placing an $\mathbf{X}$ in the appropriate box where $1=$ strongly agree, $2=$ agree, $3=$ undecided, $4=$ disagree, $5=$ strongly disagree

\begin{tabular}{|l|l|l|l|l|l|l|}
\hline & Demographic Influence & 1 & 2 & 3 & 4 & 5 \\
\hline DI1 & My gender has influence on my use of a computer & 1 & 2 & 3 & 4 & 5 \\
\hline DI2 & My age has an influence on my use of a computer & 1 & 2 & 3 & 4 & 5 \\
\hline DI3 & My race has an influence on my use of a computer & 1 & 2 & 3 & 4 & 5 \\
\hline DI4 & My home location has influenced my use of a computer & 1 & 2 & 3 & 4 & 5 \\
\hline DI5 & $\begin{array}{l}\text { Location of the High School I attended has had an influence on my computer } \\
\text { use }\end{array}$ & & & & \\
\hline DI6 & Gap years before varsity enrolment have had influence on my computer use & 1 & 2 & 3 & 4 & 5 \\
\hline DI7 & My current level of study has had an influence on my use of a computer & 1 & 2 & 3 & 4 & 5 \\
\hline & Basic Computer skills & 1 & 2 & 3 & 4 & 5 \\
\hline CS1 & I am able to navigate through a computer without assistance & 1 & 2 & 3 & 4 & 5 \\
\hline CS2 & I can update my computer profile settings without any assistance & 1 & 2 & 3 & 4 & 5 \\
\hline CS3 & I am able to download study materials and course grades & 1 & 2 & 3 & 4 & 5 \\
\hline CS4 & I am able to upload files by using a computer & 1 & 2 & 3 & 4 & 5 \\
\hline CS5 & I am able to access feedback from lecturers on a computer & 1 & 2 & 3 & 4 & 5 \\
\hline CS6 & I am able to respond to online quizzes on a computer & 1 & 2 & 3 & 4 & 5 \\
\hline CS7 & I know how to send and access emails & 1 & 2 & 3 & 4 & 5 \\
\hline CS8 & I can create documents using Word Processing & 1 & 2 & 3 & 4 & 5 \\
\hline CS9 & I can create spreadsheets and charts in Excel & 1 & 2 & 3 & 4 & 5 \\
\hline CS10 & I can create presentations using PowerPoint & &
\end{tabular}




\begin{tabular}{|c|c|c|c|c|c|c|}
\hline CS11 & I can use Online library resources & 1 & 2 & 3 & 4 & 5 \\
\hline & \multicolumn{6}{|l|}{ Perceived usefulness } \\
\hline PU1 & I find a computer useful for learning & 1 & 2 & 3 & 4 & 5 \\
\hline PU2 & Using a computer makes my learning more effective & 1 & 2 & 3 & 4 & 5 \\
\hline PU3 & Using a computer helps me to improve my academic performance & 1 & 2 & 3 & 4 & 5 \\
\hline PU4 & Using a computer enables me to accomplish tasks more quickly & 1 & 2 & 3 & 4 & 5 \\
\hline \multirow[t]{2}{*}{ PU5 } & Using a computer adds a lot to my development as a teacher & 1 & 2 & 3 & 4 & 5 \\
\hline & \multicolumn{6}{|l|}{ Perceived ease-of-use } \\
\hline PEOU1 & Learning to use a computer was easy for me & 1 & 2 & 3 & 4 & 5 \\
\hline PEOU2 & I found a computer easy to use & 1 & 2 & 3 & 4 & 5 \\
\hline PEOU3 & It was easy to become skilful at using a computer & 1 & 2 & 3 & 4 & 5 \\
\hline PEOU4 & My interaction with a computer is clear and understandable & 1 & 2 & 3 & 4 & 5 \\
\hline \multirow[t]{2}{*}{ PEOU5 } & I find it easy to navigate through most of a computer's tools & 1 & 2 & 3 & 4 & 5 \\
\hline & \multicolumn{6}{|l|}{ Access to computers } \\
\hline $\mathrm{AC} 1$ & I own a computer (either a desktop, laptop, smartphone, or other) & 1 & 2 & 3 & 4 & 5 \\
\hline $\mathrm{AC2}$ & I have access to a computer any time I need one & 1 & 2 & 3 & 4 & 5 \\
\hline $\mathrm{AC} 3$ & I am able to use a computer any time I need to & 1 & 2 & 3 & 4 & 5 \\
\hline AC4 & There are no barriers to my using computers in the computer labs & 1 & 2 & 3 & 4 & 5 \\
\hline AC5 & I have access to computers installed at the library & 1 & 2 & 3 & 4 & 5 \\
\hline AC6 & I learned by using computers at school & 1 & 2 & 3 & 4 & 5 \\
\hline AC7 & I enjoy using computers & 1 & 2 & 3 & 4 & 5 \\
\hline \multirow[t]{2}{*}{$\mathrm{AC} 8$} & I chat often on social networks & 1 & 2 & 3 & 4 & 5 \\
\hline & \multicolumn{6}{|l|}{ Actual computer use } \\
\hline AU1 & I can login to a computer without assistance & 1 & 2 & 3 & 4 & 5 \\
\hline AU2 & On average I spend more than an hour each time I login to a computer & 1 & 2 & 3 & 4 & 5 \\
\hline AU3 & Most of my notes are on the computer & 1 & 2 & 3 & 4 & 5 \\
\hline AU4 & All my assignments are done on a computer & 1 & 2 & 3 & 4 & 5 \\
\hline AU5 & I write most of my tests and examinations on a computer & 1 & 2 & 3 & 4 & 5 \\
\hline \multirow[t]{2}{*}{ AU6 } & I use a computer in my different learning activities & & & & & \\
\hline & \multicolumn{6}{|l|}{ Computer self-efficacy } \\
\hline CSE1 & I can use a computer even if there is no one to show me how to do it & 1 & 2 & 3 & 4 & 5 \\
\hline CSE2 & I can use a computer even if I have never used it before & 1 & 2 & 3 & 4 & 5 \\
\hline CSE3 & I can use a computer if I have only the online instructions for reference & 1 & 2 & 3 & 4 & 5 \\
\hline CSE4 & I can use a computer if I have seen someone else use it before & 1 & 2 & 3 & 4 & 5 \\
\hline CSE5 & I can use a computer if I am given time to familiarise myself with it & 1 & 2 & 3 & 4 & 5 \\
\hline CSE6 & I can use a computer if someone shows me how to do it & 1 & 2 & 3 & 4 & 5 \\
\hline CSE7 & I can use a computer if I have used a similar system before & 1 & 2 & 3 & 4 & 5 \\
\hline CSE8 & I can use a computer if I have the built-in help facility for assistance & 1 & 2 & 3 & 4 & 5 \\
\hline \multirow[t]{2}{*}{ CSE9 } & I believe I have the ability to install the software on a computer & 1 & 2 & 3 & 4 & 5 \\
\hline & \multicolumn{6}{|l|}{ Social Influence } \\
\hline SI1 & My friends think that I should use a computer for my studies & 1 & 2 & 3 & 4 & 5 \\
\hline SI2 & My lecturers think that I should use a computer for my studies & 1 & 2 & 3 & 4 & 5 \\
\hline SI3 & My colleagues at the university think that I should use a computer & 1 & 2 & 3 & 4 & 5 \\
\hline SI4 & Important people to me think that I should use a computer & 1 & 2 & 3 & 4 & 5 \\
\hline SI5 & My peers think that I should use a computer for my studies & 1 & 2 & 3 & 4 & 5 \\
\hline
\end{tabular}

